\title{
Effect of contract tobacco farming on the welfare of smallholder farmers in Angonia District, Mozambique
}

\author{
Inácio Modesto Cipriano ${ }^{1^{\star}}$, Isaac Mambo ${ }^{2}$ and Charles Masangano ${ }^{2}$ \\ ${ }^{1}$ Department of Rural Sociology, University of Eduardo Mondlane- ESUDER, Mozambique. \\ ${ }^{2}$ Department of Rural Development and Extension, Lilongwe University of Agriculture and Natural Resources \\ (LUANAR), Malawi.
}

Received 7 July, 2017; Accepted 22 September, 2017

\begin{abstract}
The use of contract farming, which constitutes a subject of current debates, especially on the issue of whether or not participating farmers improve their welfare and thus contribute to the local economy as an agricultural intervention is being adopted by many African countries including Mozambique. The Mozambique government adopted contract farming which is being implemented in the central region, mainly involving production of cash crops (Tobacco, cotton and sugarcane) using smallholder farmers. To this end, this study was carried out to assess the effect of contract tobacco farming on the welfare of smallholder farmers in the district of Angonia in Mozambique. Data were collected using questionnaire from 359 randomly selected farmers. Checklists with 27 focus group discussions, 67 key informants' interviews were also used. The results show that some farmers are able to improve their welfare as a result of their participation in contract farming. Although farmers are motivated by income generation, the contractor offers low prices which result in low returns and debts accumulation by farmers. Considering these, the study concludes that contract tobacco farming is dysfunctional, as it fails to improve the welfare of farmers. The findings of this study offer guidance on how contract farming should be organised so that both parties involved in contract can benefit and improve the chance of a win-win situation. The study further generates useful information that evaluates the subsector in terms of its contributions to the local economy.
\end{abstract}

Key words: Contract tobacco farming, welfare of farmers.

\section{INTRODUCTION}

The concept of contract farming emerged in the 1980s, as a strategy for rural transformation in Africa (Watts et al., 1988; Bellemare, 2012). The strategy advocates the interaction between small and large-scale producers who both look for benefits without sacrificing the rights of either party (Watts et al., 1988). Proponents of contract farming perceive it as a means to increase welfare for farmers in developing countries (Bellemare, 2012). Some

*Corresponding author. E-mail: cipriano12cipriano@gmail.com Tel: +258826905168.

Author(s) agree that this article remain permanently open access under the terms of the Creative Commons Attribution License 4.0 International License 
argue that it is relevant to food policy decision-making, because the system has pro-poor impact. Such arguments highlight that farmers ensure food security, and they mostly tend to experience positives effects, especially when revenues from contract farming enable them to meet their household expenses (Barratt et al., 2003; Miyata et al., 2009; Barrett et al., 2012).

Despite significant efforts made by the government towards poverty reduction through agricultural production, the economic welfare of smallholder contract farmers in Mozambique remains vulnerable, given the fact that almost 10 million people live in absolute poverty, suffering from food insecurity, low incomes and unemployment (Ministry of Agriculture, 2011; Pauw et al., 2011). Rural poverty in Mozambique is on the rise due to limited development in agriculture, along with limited access to markets and low productivity of food and cash crops (Ministry of Agriculture, 2011).

As a strategy to alleviate rural poverty, the government of Mozambique launched its Strategic Plan for Agricultural Development (PEDSA) in 2011, with the objective of contributing towards food security and increased income for agricultural producers, in a competitive and sustainable way, and at the same time guaranteeing social and gender equity (Ministry of Agriculture, 2011).

One of the strategies adopted by PEDSA is the Mozambique Leaf Tobacco Company (MLTC), which produce tobacco involving smallholder farmers. This is in accordance with the Decree 176/2001/Act 12, in which the government recognises the value of tobacco production in the country. Through this approach, the government credits the MLTC for exercising contract tobacco farming, with the understanding that allowing companies to operate contract tobacco farming, will contribute to increased farmers' incomes and enable the integration of the global tobacco market, as well as promote the participation of the private sector in contract farming (Decree 176/2001 Act 12).

Tobacco farming is an activity that generates export earnings, and promotes local economic development. It is one of the major sources of income, uplifting the welfare for more than 129,755 farmers in the central and northern regions of Mozambique. On average, the tobacco subsector contributes close to $34 \%$ of the total agricultural exports and almost $4 \%$ of the total exports of goods and services (Benfica et al., 2004). Overall, tobacco is one of the most important agricultural export crops in Mozambique, accounting for $7.8 \%$ of total exports in 2011 (Hu and Lee, 2015).

While the government believes that tobacco, as a cash crop, enables farmers to increase their purchasing power and raise their household standard of living above poverty level, contract tobacco farming has received mixed reviews. According to Miyata et al. (2009), contracted tobacco farmers improve their income and livelihoods, which lead to reducing absolute poverty, when compared with non-contracted tobacco farmers. Moreover, tobacco production overcomes market imperfections and shortage of agricultural inputs for smallholder farmers and the poor (Barrett et al., 2012).

On the other hand, Hu and Lee (2015) argue that the individual small tobacco farmer lives in poverty because the tobacco production does not benefit them, but benefits the intermediaries or the middlemen, instead. Tobacco farmers receive inputs from the tobacco leaf company, hoping to earn cash income. However, the tobacco leaf company, which grades the leaves and set prices, purchase their harvest at a set low price. As a result, the contract tobacco farmers end up with a negative income, after they use their meagre revenue to pay their loans for the inputs received from the company.

Similarly, Miyata et al. (2009) and Chepkurui and Kinoti (2014) argue that contract tobacco farming is a way of companies using cheap labour and transferring production risks to farmers. Other studies have shown that the returns from alternative crops such as corn are higher than the returns from contract tobacco farming in Mozambique (Abdurramane, 2007; Hu and Lee, 2015).

Given the diverging views of the effects of contract tobacco farming on the welfare of smallholder farmers, this study aims at assessing the roles of different stakeholders and other factors involved in contract tobacco farming, for a clearer understanding of the effect of contract tobacco farming on the welfare of smallholder farmers in the Angonia district in Mozambique.

\section{Study objectives}

The principal objective of this study is to analyse the effect of contract tobacco farming on the welfare of smallholder farmers in the district of Angonia (Mozambique). Specifically, the study aims to:

(1) Identify the roles of different stakeholders in contract tobacco farming,

(2) Identify the reasons influencing the participation of smallholder farmers in contract tobacco farming, and

(3) Assess the effect of contract tobacco farming on the welfare of participating farmers.

\section{METHODOLOGY}

\section{Study area}

The study was conducted in the district of Angonia, which is located in the north-western part of Mozambique, bordering Malawi.

According to the 2005 census, the population of Angonia approximates 330,378 people (Ministry of State Administration, 2005). Agriculture is the most important economic activity practiced in the area, contributing one-quarter of the gross domestic product (GDP), and employing $80 \%$ of the rural adult population. Tobacco is one of the cash crops cultivated by smallholder farmers, both men and women. The district of Angonia was chosen for the study 
because of its favourable agro-ecological conditions for tobacco production, and for accessibility to tobacco processing facilities in a nearby district.

\section{Research design}

The study was an evaluation impact design, which consisted of a descriptive survey method to assess:

(1) The effect of contract tobacco farming on the welfare of participating farmers.

(2) The contractor's compliance with the terms of contract farming, and

(3) The government's actions or interventions in contract farming.

Specifically, the study aimed to assess issues related to income distribution and physical welfare (availability of food, assets, education level, occupation, health care, household improvement and skill gaining) of participating contract farmers. The contractor was evaluated in terms of honour of the contract, inputs supply, technical assistance, risks sharing, market availability, prices and some cross cutting issues (corruptions). The government was evaluated in terms of legal framework, transfer of technologies and research activities, especially to identify occurrences of social and organisational programmes or interventions. The study approach was chosen because it enables an in-depth understanding of nature of the context by examining the causal factors that inhibits or promotes changes within contract tobacco farmers (Bryman, 2012).

\section{Sampling technique}

The present study used probability sampling technique, in which the respondents had the same chance or probability of being selected. To ensure this, the study used random sampling without replacement (Cochran, 1977).

\section{Sample size determination}

The MLTC contracted with about 10,000 farmers to grow tobacco in Angonia district. These farmers are divided into two sections, based on regions: one section with 5,600 farmers and the other with 3,400 . The sample size (n) of tobacco growers was determined based on the following formula (Cochran, 1977):

$n=\frac{z^{2}(1-p) p}{e^{2}}=\frac{(1.96)^{2}[(1-(.5)](.5)}{(.05)^{2}}=384$ Tobacco farmers $(1)$

where $Z=1.96$ for $95 \%$ level of confidence, $e=0.05$ for margin of error, $\mathrm{p}=$ proportion of contract tobacco growers, $\mathrm{n}=$ sample size. The sample size formula for the finite population is given as:

$\mathrm{N}=\frac{n}{1+\left(\frac{n-1}{p O P}\right)}=\frac{384}{1+\left(\frac{384-1}{5600}\right)}=35$ Tobacco farmers

$\mathrm{N}$ is the sample size of finite population; $\mathrm{n}$ is the sample size calculated from infinite population; and Pop is the population. Calculating from the above formula, a sample of 359 contract tobacco farmers was obtained (Cochran, 1977).

\section{Sampling design}

First, the list of all villages producing tobacco under contract was obtained, and then 27 villages were randomly selected from the list, followed by household simple random sampling. Club leaders in each of the 27 villages helped identify members who participate in contract tobacco farming. From there 359 farmers, representing 13 to 14 farmers per village, were selected and administered an individual survey questionnaire, and a checklist in groups. Focus group discussions were organized immediately following the questionnaire survey. In addition, key informants composed of a government respondent, three non-governmental organisations (NGOs): (one each from Total Land Care, International Institute Tropical Agriculture (IITA) and Society of Jesus (SJ); one government extension worker and two tobacco extension workers were interviewed to provide their independent opinions concerning tobacco contract farming. Similarly, 60 randomly selected nontobacco contract farmers from the 27 villages (2 to 3 per village) were surveyed to determine their perceptions of contract tobacco farmers. These include community leaders and ex-contract farmers, and they were also considered as key informants, for the purpose of the study.

\section{Data collection methods}

\section{Individual interviews}

Individual interviews were structured to cover different sections, including identification of participants, socioeconomic characteristics of households, tobacco production, food security, and land use. The variables were measured at nominal level in which symbols were used to classify observations into mutual categories. The interviewers used interpersonal skills such as questioning, conversing and listening to provide an understanding of social phenomena. During data collection, special attention was also given to how people responded to the questions and how the interviews were conducted and recorded (Gill et al., 2008). These measures/approaches are necessary to ensure the quality of data in the study. As for tools, the study used survey questionnaires for 359 small households; and two (2) sets of checklists: one for 27 focus group discussions, and another one with 67 key informants. The survey questionnaire was designed to gather socio-economic and demographic information, while the checklists were based on the specific objectives of the study. To ensure content validity and usability, both the questionnaires and the checklists were developed in consultation with the experts in the area of tobacco production and supervisors of the study.

\section{Focus group discussions}

Qualitative methods using semi-structured interviews were also used to collect data. Semi-structured interviews consisted of several key questions that explored specific area of interest. They allowed interviewees and interviewers to diverge where necessary in order to pursue responses in more detail. The checklist covered areas such as access to knowledge and skill gaining in tobacco contract farming, third parties involvement and their roles in tobacco contract farming, how contract farming is implemented by the MLTC, marketing and input supply. Again, variables were measured through classification of responses into categories. Using semistructured interviews, focus group discussion took the form of focus groups with multiple participants sharing their experiences on specific subject matter oriented by the objectives of the study (Bloom and Crabtree, 2006). Focus group discussions were used to generate collective views and the meanings behind those views. Focus group discussions then provided evaluative ideas of the topic. Moreover, focus group discussions were used to understand the process and meanings to the group norms relating to tobacco cultivation. These were always facilitated by two people each of 
whom had specific responsibilities: one was the moderator of the discussions, another one took notes. Hence, the study employed the method of Gill et al. (2008), who stated that successful focus group discussions work with as few as 3 and as many as 14 participants.

\section{Key informants' interviews (KII)}

The purpose of key informants' interviews was to gather information from people with diverse backgrounds and opinions, who were considered informed experts, based upon their particular knowledge and understanding of contract tobacco farming (Carter and Beaulieu, 1992). The inclusion of key informants was to gather independent ideas on the value or effect of contract tobacco farming.

\section{Qualitative analysis (focus group discussion data)}

Given the nature of the study, content analysis was used to quantify content in terms of predetermined categories in a systematic manner (Bryman, 2012). To this regard, the data underwent categorisation of verbal or behavioural data for the purpose of classification, summarisation, and tabulation in order to produce quantitative accounts of raw material in terms of categories. Moreover, qualitative data was organized into major and minor categories (themes); comparing and contrasting of major and minor categories to avoid repetition. After this, data were entered into a computer in order to be labelled and coded, counted and analysed into Statistical Package for the Social Science (SPSS 20.0.) (Bhattacherjee, 2012). This process resulted in frequencies and percentages through descriptive statistics. Analysis of key informants' checklist responses was done by assigning each participant comments or quotes, the meanings of which were then brought to the presentation of the results and discussion. This means that data from key informants did not go through classification, summarisation and tabulation. The purpose of this was to bring live meaning and expressions of key informants into discussion.

\section{Quantitative analysis (questionnaire data)}

Quantitative method measured numerical comparison and statistical inferences (Casley and Kumar, 1988). Questionnaire survey data were labelled and coded to facilitate entry into computer for analyses using Statistical Package for the Social Science (SPSS 20.0.) and Excel 2013, for Descriptive Statistics (Bhattacherjee, 2012).

\section{RESULTS AND DISCUSSION}

\section{Role of stakeholders in contract tobacco farming}

\section{The government}

The government of Mozambique and Total Land Care (TLC) were considered as the other actors in contract tobacco farming, besides the contractor and the farmers. The participation of TLC and the government is explained in terms of their roles in contract tobacco farming. According to Eaton and Shepherd (2001), government has an important role of protecting farmers who are faced with the risk, enforce legal framework and ensure that financial and managerial obligations are followed if contract farming is to be successful. Enforcing the legal framework requires clear mechanisms such as practical guidelines that explain when the government should act on which legal basis.

Table 1 shows the results on the role of the government in contract tobacco farming, as reported by the farmers in focus group discussion. The results show that in 16 out of 27 villages, tobacco contract farmers demonstrated knowledge on the question of the role of government. There were 22 responses of which $59.1 \%$ of the farmers indicated that they are aware of the role of the government, which is mainly to "protect them". The government also knows its role, as confirmed by a government key informant: "the government is like a labour union that tries to protect farmers from risks or problems that might occur between the parties". However, the observation from the field is that farmers are unhappy with the role of the Government. They reported that the "government only needs us when it is time for the electoral campaign". Farmers requested the government to help them solve the issue of corruption during the grading period and to negotiate better prices of tobacco. The interpretation is that the government assistance is limited because the issues of negotiating better price and corruption during the grading period have been the cause of conflict between the farmers and the company.

In addition, a respondent from the government when asked whether the district holds any document as law and policy that regulates the contract tobacco farming in practice, the district respondent reported that "I have not seen any document"; and the provincial respondent provided the strategic plan document (PEDSA). It was therefore, understood based on the above government responses, why farmers complained about corruption.

The manner in which Mozambique exercises contract tobacco farming makes it difficult to understand why its policy encourages companies to work in the country on the basis of contracting schemes when the government itself does not support contract farming in practice. Bronwyn et al. (2012) has argued that a successful contract scheme should be based on harmonised laws and policy that are clearly written incorporating the necessities of the country and context rather than basing on the general strategic plans like that of PEDSA. Such policy should show the vision, mission and principles that every company wishing to start a contract scheme should follow. This support document should be a guideline that includes all the steps a business should follow through the first activities of contract. Not having a support document endangers the welfare of the farmers, as it depends not only on economic variables or good agricultural practices, but also on policy implemented on the ground.

As shown in Table 1 , only 16 out of 27 villages had 
Table 1. The role of the government in contract farming.

\begin{tabular}{lcc}
\hline Role & Frequency & Percentage $(\mathbf{n}=\mathbf{1 6})$ \\
\hline Protect the farmers (including protection from corruption) & 13 & 59.1 \\
Transfer of technologies & 5 & 22.7 \\
Research & 2 & 9.1 \\
Bring in additional tobacco companies in the country & 1 & 4.5 \\
Coordinating MLT and farmers & 1 & 4.5 \\
Total & 22 & 100.0 \\
\hline
\end{tabular}

knowledge of the government's role, and 11 villages representing $40.7 \%$ had no knowledge. Again, this reenforces the argument that the farmers had no knowledge of role of the government. In line with this, farmers recommended that the government should protect them from market, and negotiate better prices accordingly. Unfortunately, this cannot be done successfully, if the laws and policies concerning contract tobacco farming are not properly implemented and enforced.

Still on the recommendations, the farmers advised that the government should conduct research (9.1\%) in contract tobacco farming in order to evaluate its contribution to the welfare of smallholder farmers. While a government informant mentioned that the government acts as labour union that solve the problems arising between the farmers and the contractor, the farmers feel unprotected and left behind by the government. Therefore, doing research could be a way of trying to protect not only the farmers, but also the contractor. The recommendation seems pertinent because the findings of any kind may contribute to improving the welfare of the farmers.

Another important issue that came out from the farmers is about technology transfer $(22.7 \%)$. Farmers showed satisfaction in terms of technical assistance they received, including extension services. However, the government should pay attention to technologies that the contractor does not wish to provide, for example, assistance in intercropping, technologies which relate to processing and others. In fact, many contractors dislike offering some of these technologies because they are not part of their business. Rather, contractors capitalise on good tobacco quality for their productive business. However, if government supplements technologies that the farmers lack, to improve operations of contract tobacco farming, farmers will be able to improve their welfare.

\section{The total land care (TLC)}

Contracted tobacco farmers mentioned that the main role of TLC is afforestation (50\%) followed by seed provision and supervision (25\%). The TLC offers trees to be planted in the plots that had already been used for tobacco production in previous years and in so doing, restore soil fertility. However, trees are given to farmers on credit basis. Unfortunately, some farmers reported that they were not able to receive the trees because they did not have enough land for fallow, and insufficient money to pay for the loan. The TLC also provided other agricultural inputs on credit such as agro-chemicals $(16.7 \%)$, and helps farmers build small dams $(8.3 \%)$ for cultivation of other crops during dry season. However, some farmers reported that they were not provided with such assistance. This suggests that neither the MLTC nor the TLC were able to provide agro-chemicals to all participating farmers, as it calls for the government to provide inputs that the contractor could not provide. Figure 1 summarizes the relationship between the contractor, government and TLC. As shown in Figure 1, the MLTC communicates directly with the farmers and administers contract to them. The MLTC uses and finances the services of TLC for afforestation and other services. Since the government is the entity that gives the companies a monopsony, it trusts the company to work with farmers according to the project presented to it. As mentioned previously, the government's role is limited; its involvement is not felt by the farmers and above all, communication between farmers and the government is almost inexistent. This leaves the farmers vulnerable, as they lack protection from the government through regulations.

\section{Factors influencing smallholder farmers to participate in contract tobacco farming}

Contract farmers were asked during the survey to provide the reasons that motivated them to join the contract tobacco farming; and those who dropped out of contract tobacco were asked to provide their reasons for doing so. Table 2 shows the reasons why farmers joined the contract farming as reported by those in focus group discussions.

There were thirty-eight (38) responses from all 27 villages on the question pertaining to the reasons influencing farmers to join contract farming. As shown in Table 2, an overwhelming $55.3 \%$ of respondents 


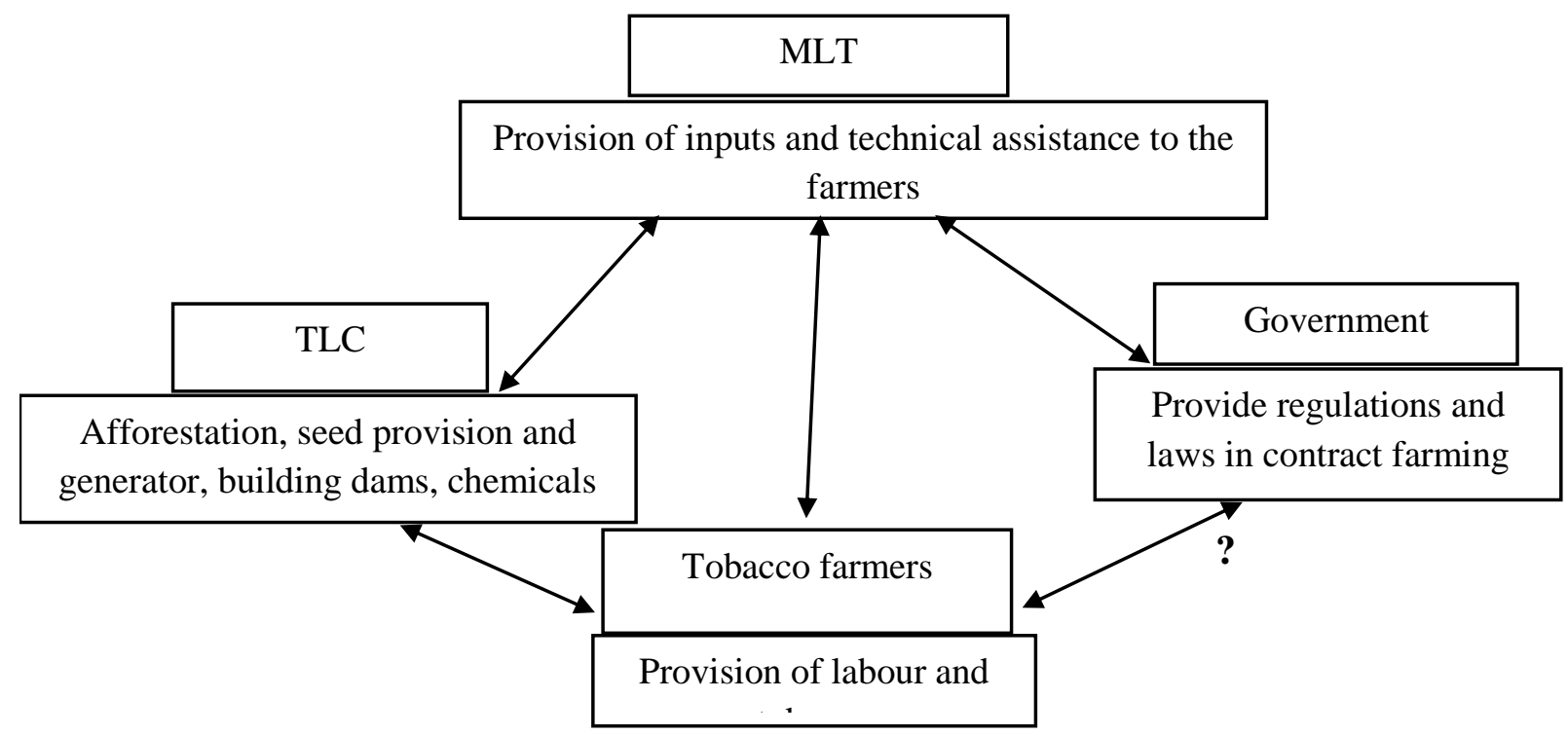

Figure 1. The relationship among the MLTC, TLC, government, the farmers and their roles.

Table 2. Reasons why farmers joined contract tobacco farming.

\begin{tabular}{lcc}
\hline Reason & Frequency & Percentage $(\mathbf{n}=\mathbf{2 7})$ \\
\hline Income generation & 21 & 55.3 \\
Occupation & 7 & 18.4 \\
Learn new technology & 5 & 13.2 \\
No other contract company & 3 & 5.3 \\
To get easy access to inputs & 1 & 2.6 \\
Just for fun & 1 & 2.6 \\
Total & 38 & 100.0 \\
\hline
\end{tabular}

identified "Income Generation" as the principal reason for influencing farmers to participate in contract tobacco farming. Interestingly, one of the factors motivating farmers to participate in contract farming is their inability to access production tools and materials on their own. Therefore, if one could separately offer farmers the means of production, would they still opt to produce tobacco or produce crops other than tobacco? Considering some complaints from farmers in the field, one would argue that some farmers would give up the contract if they acquire the means of production from sources other than the tobacco contractor. Given that some farmers were unhappy with the contract, the study went further to assess the retention of farmers under tobacco contract farming. The results presented in Table 3 show the reasons why some farmers dropped out of contract tobacco farming as reported in focus group discussions.

Thirty-five survey participants from 26 villages responded to the question of why farmers are giving up contract tobacco farming. The results show that $45.7 \%$ of them stated low income and $20 \%$ identified debts accumulation, as the main factors influencing farmers to leave the contract farming (Table 3 ). These results indicate that some farmers do not generate enough revenues through contract tobacco farming, which is attributable to high cost of farm inputs and poor agricultural management. Generally, farmers do not manage two production fields at the same time; that is, one for staple food and another for cash crop (tobacco production). Barrett (2012) observed that farmers moved in and out of contracts because of food security and risks associated with markets structure. This was confirmed by a key informant who reported that "farmers have reduced food crop production in the last decade because of tobacco growing". This means that farmers used to have surplus of food, which is not observed after farmers joined contract tobacco farming.

This study establishes that though farmers consider contract farming as the main activities to ensure food security, tobacco production does not contribute to this end. It is for this reason that the majority of farmers 
Table 3. Reasons why farmers left contract tobacco farming.

\begin{tabular}{lcc}
\hline Reason & Frequency & Percentage $(\mathbf{n}=\mathbf{2 6})$ \\
\hline Low income & 16 & 45.7 \\
Debts accumulation & 7 & 20.0 \\
Low market prices & 5 & 14.3 \\
Corruption & 3 & 8.6 \\
Labour intensive tobacco demands & 3 & 8.6 \\
Difficult to adopt technologies & 1 & 2.8 \\
Total & 35 & 100.0 \\
\hline
\end{tabular}

Table 4. Positive changes that farmers experienced after they joined contract tobacco farming.

\begin{tabular}{lcc}
\hline Positive effect & Frequency & Percentage $(\mathbf{n}=\mathbf{2 9 0})$ \\
\hline Be able to meet family expenses (food, clothes, education and health) & 231 & 46.9 \\
Capacity to buy household assets (radio, bicycle, motorbike and oxcart) & 63 & 12.8 \\
Improved income & 59 & 12.0 \\
Be able to buy livestock & 53 & 10.8 \\
Have a means of livelihood & 14 & 2.8 \\
Household improvement & 33 & 6.7 \\
Acquired some good agricultural practices skills (farm management techniques,) & 13 & 2.6 \\
Bought agricultural inputs (access to credit of inputs) & 11 & 2.2 \\
Contributing to pay off debts & 11 & 2.2 \\
Provide readily markets & 5 & 1.0 \\
Total & 493 & 100.0 \\
\hline
\end{tabular}

Source: Questionnaire survey.

(54.3\%), reported to have meals twice per day. This shows that farmers reduce the number of meals taken into account the stock they have per year. This research will now shed more light on the changes that farmers experienced as the result of contract tobacco farming.

\section{Changes that farmers experienced after they joined contract tobacco farming}

Among the 359 contracted tobacco farmers surveyed, 290 responded to the questionnaire on "changes perceived by farmers after they joined contract farming". The questionnaire yielded 493 responses from 10 categories of perceived changes (Table 4). The majority of farmers $(46.9 \%)$ responded that they experienced positive changes as a result of being in contract tobacco farming; and were able to invest in education and household assets, food and health. These results are consistent with the findings of the previous studies by Barratt et al. (2003), Benfica et al. (2004), Miyata et al. (2009), and Barrett et al. (2012) who found that contracted tobacco farmers tend to invest in home improvement, education, healthcare, buy durable goods (radios, bicycles, motorcycles) and clothes. Moreover, the finding is also consistent with what is mostly reported by the mass media, the government and tobacco officials who believe that contracted tobacco farmers improve income.

Nonetheless, Glover and Kusterer (1990) argued that few farmers buy things of high value; therefore, such investment does not create noteworthy impacts. Similarly, this study established that farmers could only afford to buy food for a short period of time. Thus, the stock of food that farmers possess is not enough to cover the 12 months each year. Farmers themselves affirmed that in order to cope with the situation of hunger, they work on someone's garden in addition to tobacco contract farming, to receive food or money to purchase food. With regard to short-term investment, a question arises as to whether buying clothes creates a real positive effect on the welfare of an individual. On the other hand, though education can be recognised as a long-term welfare of households, can investment in education create a direct and measurable effect on the farmers' lives? These and many other questions need to be given appropriate attention, suggesting that an assessment should be done over time, as opposed to a "snapshot" of farmers at a single point in time.

Moreover, Table 4 shows that $12.8 \%$ of respondents stated positive changes in house improvement as the result of their participation in contract tobacco farming. 
Table 5. Negative effects of tobacco contract farming.

\begin{tabular}{lcc}
\hline Negative effects & Frequency & Percentage $(\mathbf{n}=\mathbf{3 0 4})$ \\
\hline Labour intensive and time consuming & 172 & 38.4 \\
Getting low prices offered by MLTC & 169 & 37.7 \\
Corruption and attribution of wrong grading & 54 & 12.1 \\
Exposure to pesticides & 21 & 4.7 \\
High cost of inputs (crop spray and fertilisers) & 10 & 2.2 \\
Climate related shocks/poor rainfall patterns & 10 & 2.2 \\
Hard to adopt some technologies & 4 & 0.9 \\
Lack of legal framework to protect farmers & 4 & 0.8 \\
Cumulative debts & 3 & 0.7 \\
Transportation problems & 1 & 0.2 \\
Total & 448 & 100.0 \\
\hline
\end{tabular}

However, it should be noted that house improvement was associated with many factors: Farmers may buy roofing material with revenues from contract farming, but they make bricks by themselves, use trees from their own farm, and build the house with the help from other members of the community or from relatives.

Table 4 further shows that $1 \%$ of farmers who responded to the questionnaire do not see "readily market" as an important aspect of contract tobacco farming (that overcomes market imperfection). Located along the borders of Malawi and Zambia, farmers in the study area have many market options. Even though side selling is strictly not allowed, farmers could export their tobacco products to Malawi and Zambia, in case the company fails to buy them, as stated by key informants during the study. Table 5 shows the negative effects of contract tobacco farming as reported in questionnaire survey.

Out of 359 contracted tobacco farmers surveyed, 304 responded to the question of negative effects of contract tobacco farming. There were a total of 448 responses and from these, $37.7 \%$ reported that the MLTC offers low prices, and $38.4 \%$ indicated that contract tobacco farming is labour intensive. A comparative study by Dias (2013) of four countries (Malawi, South Africa, Kenya and Mozambique) also concluded that the price paid to farmers in Mozambique is lower than the prices in the other three countries. As observed from the field during this study, low tobacco price is the source of conflict between the farmers and the contractor, which is resulting in unhealthy relationship. Consequently, farmers do not stay loyal to the company.

Buying tobacco at low prices is an unequal exchange whereby big companies such as these exchange primary goods produced with labour at below subsistence cost for manufactures produced with non-competitive expensive labour; and as such, the exchange value of primary goods is below the true value.

The question then arises as to why farmers should be allowed to participate in a business where their welfare is at risk? Actually, contract farming in the Angonia district contributes to the impoverishment of farmers, partly because of problems associated with the monopsony system in place. First, the buyer has total control over the price and quality; second, the buyer can break the contract without penalty, and third, the government has to approve the monopsony system that presently creates space for corruption (Smart and Hanlon, 2014).

\section{Conclusion}

Based upon the results of this study, farmers receive training on good husbandry for tobacco production, and they receive inputs on credits, all within the expectation that they will improve their welfare. However, this study concludes that the skills and technologies that the farmers acquired, did not translate into improved welfare. Instead, farmers appeared to be the losers in the contract tobacco farming scheme implemented in the district of Angonia in Mozambique.

Essentially, farmers are motivated to join in contract tobacco farming and mainly invest to increase their income and thus, their welfare. Few of the farmers who experience increased income, invest mainly in durable goods and after that, end up with no money and nothing in their possession; it is rather a temporal investment. The study recommends that farmers should be trained on how to invest their money.

Although farmers are motivated to enter into contract tobacco farming because of income generation, the contractor offers low prices, resulting in farmers getting low returns. In addition, contract tobacco farming results in debt accumulation by farmers due to high cost of inputs, and this induces poverty rather than alleviating poverty. The monopsony system contributes to an unequal relation that exploits farmers and benefits the contractor. Given these and other effects, the study concludes that contract tobacco farming is dysfunctional if not, non-beneficial to the farmers. It fails to promote the 
welfare of farmers, which is measured by the progress in terms of wellbeing, including income generation (that is not fulfilled), and food security (that is inefficient to cover 12 months in a year), and the like.

For contract tobacco farming to be beneficial for both the farmers and the contractor, the government of Mozambique should regulate it in practice. The government should develop clear written policies and guidelines to provide the context of contract tobacco farming in the country. The policy guidelines should show rationale for developing the policy, vision, mission, principles, optimal farmer's selection, records and management systems. This will prevent problems such as lack of prices information, conflicts between the farmers and the contractor. Besides, farmers should improve negotiation power by forming an organisation to protect their interests and solve problems such as corruption when grading tobacco. Thus, the government cannot address contract farming issues with each individual farmer, but rather with the group. Again, this will increase an opportunity for farmers to participate in decision-making, with regard to price determination for tobacco. Limited government role in contract tobacco farming increases the power of the company to control farmers and production. In this scenario, farmers are subordinates and their earning does not compensate the labour and the use of their land for to the company.

\section{CONFLICT OF INTERESTS}

The authors have not declared any conflict of interests.

\section{ACKNOWLEDGEMENT}

This work was made possible through the financial support from the Ministry of Science and Technology of Mozambique.

\section{REFERENCES}

Abdurramane H (2007). Produção de Culturas de rendimento e seu Efeito na Produção de Culturas Alimentares Básicas: $O$ caso de Tobaco nas Provincias de Niassa, Zambeze e Tete. A BSc. Thesis, Eduardo Mondlane University, Maputo.

Barratt S, Erol C, Olwen G, Haluk K, Mauro de Rezende L, Thor L, Sat M, Brian M, Shangnan S, Ping Z (2003). Issues in Global Tobacco Economy: Selected Case Studies. Rome: Food and Agriculture Organisation of the United Nations. Available: http://www.fao.org/3/ay4997e.pdf, [Accessed on 17 June 2014].

Barrett CB, Maren EB, Marc FB, Hope CM, Sudha N, Walker TF (2012). Smallholder Participation in Contract Farming: Comparative Evidence from Five Countries, Revised Version. New York, USA. DOI: 10.1016/j.worlddev.2011.09.006.

Bellemare M (2012). As You Sow, So Shall You Reap: The Welfare Impact of Contract Farming. Duke University, Durham, NC, USA. DOI: $10.2139 /$ ssrn. 1595977.

Benfica R, Arlindo M, Zandamela J, De de Sousa N, De Marrule HF (2004). How to avoid killing the Chicken that Lays the Golden Eggs: An Analysis of Potential Impacts of an Export Tax on Raw Tobacco in
Mozambique.

Available

at:

http://ageconsearch.umn.edu/bitstream/55243/2/flash42e.pdf

[Accessed on June 2014].

Bhattacherjee A (2012). Social Science Research: Principles, Methods, and Practices. USF Tampa Bay Open Access Textbooks, http://scholarcommons.usf.edu/oa_textbooks/3, [Accessed on 25 August 2015].

Bloom BG, Crabtree BF (2006). The qualitative research interviews. Wiley Online Library. Blackwell Publishing Ltd. Med. Edu. 40(4):314321.

Bronwyn I, Haley S, Chishakwe N, Vitoria B, Mudonhi S (2012). Building Agricultural Markets: Constraints and Opportunities in Contract Farming for Smallholder Agricultural Economy in Zimbabwe, Harare. Harare: ASI.

Bryman A (2012). Social Research Methods. New York: Oxford University Press.

Carter KA, Beaulieu LJ (1992). Conducting a Community Needs Assessment: Primary Data Collection Techniques. Gainesville, FL: University of Florida Institute of Food and Agricultural Sciences. Available at: http://edis.ifas.ufl.edu/pdffiles/HE/HE06000 [Accessed on 02 April 2016].

Casley DJ, Kumar K (1988). The collection, analysis and use of monitoring and evaluation data. The World Bank.

Chepkurui A, Kinoti J (2014). The Social Economic Impacts of Tobacco Farming on Farmers and Household Food Security in Ang'urai Division, Kenya. Res. J. Sociol. 2(4):2347-8241.

Cochran WG (1977). Sampling Techniques. 3rd ed. New York: John Wiley \& Sons.

Dias P (2013). Analysis of Incentives and Disincentives for Tobacco in Mozambique. Technical Notes Series, MAFAP, FAO, Rome, Italy. Available at: http://www.fao.org/3/a-at577e.pdf [Accessed on 22 September 2015].

Eaton C, Shepherd A (2001). Contract Farming Partnership for growth: FAO Agricultural Services Bulletin 145, Rome, Italy. Available at: http://www.fao.org/docrep/014/y0937e/y0937e00.pdf. [Accessed on 20 December 2015]

Gill P, Stewart K, Treasure E, Chadwick B (2008). Methods of Data Collection in Qualitative Research: Interviews and Focus Group Discussion. Br. Dent. J. 204(6):291-295.

Glover D, Kusterer K (1990). Small Farmers, Big Business: Contract Farming and Rural Development, London: McMillan Press LTD, DOI: $10.1086 / 451989$.

$\mathrm{Hu}$ TW, Lee AH (2015). Tobacco Control and Tobacco Farming in African Countries. J. Public Health Policy 36(1):41-51.

Ministry of Agriculture (2011). Strategic Plan for Agricultural Development. PEDSA 2010-2019. October 2010, Government of Mozambique. Available AT: at: http://fsg.afre.msu.edu/mozambique/caadp/pedsa_finalenglish 22 nov.pdf [Accessed on 30 October 2015].

Ministry of State Administration of Mozambique (2005). Perfil do Distrito de Angonia Provincia de Tete, Available: www.govnet.gov.mz, [Acessed on 04 September 2014].

Miyata S, Monot N, Hu D (2009). Impact of contract farming on income: linking small farmers, packers, and supermarkets in China. World Dev. 37(11):1781-1790.

Pauw K, Thurlow J, Uaiene R (2011). Agricultural Growth and Poverty Reduction in Mozambique: Technical Analysis in Support of the Comprehensive Africa Agriculture Development Program. A Paper Presented on Promoting Agricultural Growth in Mozambique, Maputo. Available

http://fsg.afre.msu.edu/mozambique/caadp/Pauw_Agricultural_Growt h_and_Poverty_Reduction_in_MozambiqueENG.pdf [Acessed on 20 March 2014].

Smart S, Hanlon J (2014). Chicken and Beer: A Recipe for Agricultural Growth in Mozambique. Maputo: Kapikua. Available at: https://www.open.ac.uk/technology/mozambique/sites/www.open.ac. uk.technology.mozambique/files/files/Chickens_and_beerrecipe_for_growth_in_Mozambique.pdf. [Accessed on 20 February 2016]

Watts M, Little P, Mock C, Billings M, Jaffee S (1988). Contract Farming in Africa: Comparative. Analysis (1). New York: Institute for Development Anthropology. 